\title{
Adaptação curricular e o papel dos conceitos científicos no desenvolvimento de pessoas com necessidades educacionais especiais
}

\author{
Adriane Cenci* \\ Magda Floriana Damiani**
}

\section{Resumo}

O trabalho fundamenta-se na teoria histórico-cultural, a partir de Vygotski, e nos Parâmetros Curriculares Nacionais: Adaptações Curriculares (1998), objetivando discutir a importância da aprendizagem de conceitos científicos (os conceitos aprendidos mediante instrução formal/escolar), para o desenvolvimento dos alunos com necessidades educacionais especiais. Caracteriza-se como um ensaio teórico, apoiado em pesquisa bibliográfica. O eixo da discussão está na ideia de adaptação/ flexibilização curricular, uma vez que não há inclusão real sem considerar a individualização do ensino para atender às especificidades dos alunos. A importância atribuída ao currículo escolar e aos conceitos científicosm, nele visados, assenta-se na premissa vygotskiana de que aprendizagem promove desenvolvimento - de acordo com Vygotski, a sistematização e conscientização entram na mente da criança através do aprendizado dos conceitos científicos. Devido à importância desses conceitos, é preciso cuidado ao pensar nas adaptações curriculares; sob justificativa de adequar o ensino e o currículo às especificidades dos alunos que apresentam necessidades especiais, muitas vezes, se abre mão dos conteúdos formais, pressupondo que não estariam ao alcance desse aluno, especialmente daquele em que as dificuldades são mais acentuadas. Concluiu-se que é a aprendizagem - aprendizagem de conceitos científicos - que alavanca o desenvolvimento cognitivo, então é nesse ponto que a escolarização deve investir. É imperativo lutar por uma escola inclusiva onde, de fato, se aprenda - aprenda conteúdos.

Palavras-chave: Adaptação curricular; Conceitos científicos; Aprendizagem.

\footnotetext{
* Professora de Educação Especial pela Universidade Federal de Santa Maria - UFSM. Especialista em Gestão Educacional pela UFSM. Mestre em Educação pela UFSM. Aluna do Doutorado em Educação da Universidade Federal de Pelotas. Pelotas, Rio Grande do Sul, Brasil.

** Professora Associada da Faculdade de Educação/Universidade Federal de Pelotas (UFPel), Pelotas, Rio Grande do Sul, Brasil.
} 


\title{
Curriculum adaptation and the role of scientific concepts on the development of people with special educational needs
}

\begin{abstract}
This work is based on cultural-historical theory from Vygotsky and on the National Curricular Parameters - Curricular Adaptations (1998) - aiming to discuss the importance of learning scientific concepts (the concepts learned through formal/ academic education) to the development of students with special educational needs. It is characterized as a theoretical essay based on bibliographical research. The discussion axis is the idea of curricular adaptation/flexibility, since there is no real inclusion without considering the individualized education to meet the specific needs of students. The importance attached to school curriculum and scientific concepts referred to it is based on the Vygotskian premise stating that the learning promotes development; according to Vygotsky, knowledge systematization and awareness enter into the child mind through the learning of scientific concepts. Due to the importance of these concepts, it is needed to be careful to think about the curricular adaptations; under the justification of adapting the teaching and curriculum to the specificities of students with special needs. The formal contents are often disregarded, assuming that they would not be within the capacity scope of students, especially those ones with more pronounced difficulties. It is concluded that learning - learning scientific concepts - promotes cognitive development; then, schooling should invest at this point. It is imperative to fight for an inclusive school in which the children, in fact, can learn, learn contents.
\end{abstract}

Keywords: Curriculum adaptation; Scientific concepts; Learning.

\section{Introdução}

A inclusão escolar das pessoas com necessidades especiais é proposta que vem sendo defendida e difundida no Brasil, já há algumas décadas; porém, a partir da Política Nacional de Educação Especial na Perspectiva da Educação Inclusiva (2008) ela ganha mais força. Nesse contexto, um maior contingente de alunos com necessidades educacionais especiais tem ingressado na escola regular nos últimos anos. Esse fato coloca em relevo as especificidades do trabalho pedagógico diante das características do novo público.

Desde 1998, existe um documento publicado para orientar a inclusão de alunos com necessidades especiais em escola regular, trata-se dos Parâmetros Curriculares Nacionais: Adaptações Curriculares - estratégias para a educação de alunos com necessidades educacionais especiais (BRASIL, 1998). No entanto, apesar de já estar divulgado há alguns anos, os Parâmetros são pouco conhecidos. Considerando a relevância de tal documento para organizar a educação dos alunos 
com necessidades educacionais especiais, propõe-se aqui resgatá-lo, tomando-o também como orientador da discussão sobre o processo inclusivo.

O eixo da discussão está nos conteúdos curriculares ou, dito de outro modo, nos conceitos científicos trabalhados no ensino escolar. A ênfase atribuída aos conceitos científicos justifica-se a partir do referencial teórico, no qual se fundamenta a argumentação. Neste trabalho: a teoria histórico-cultural, cujo representante central é o russo Lev Vygostski. Ela propõe analisar o desenvolvimento do humano, levando em consideração o contexto no qual cada indivíduo se desenvolve, contexto esse que se constituiu ao longo da história de cada grupo social. A escola, em nossa sociedade, é lugar privilegiado para transmissão do legado cultural, dos conhecimentos acumulados. Na escola, os conceitos científicos figuram como a "herança" que possibilita o desenvolvimento a partir daqueles níveis já alcançados pelas gerações anteriores (VYGOTSKI, 1993).

O trabalho caracteriza-se como um ensaio teórico, que consiste "em exposição lógica ereflexiva eem argumentação rigorosa com alto nível de interpretação e julgamento pessoal" (SEVERINO, 2002, p.153). Quanto aos procedimentos, caracteriza-se como pesquisa bibliográfica (GIL, 1999).

A partir do referencial vygotskiano e dos Parâmetros Curriculares Nacionais, objetiva-se discutir a importância da aprendizagem dos conceitos científicos para os alunos com necessidades educacionais especiais.

\section{As bases da discussão: os Parâmetros Curriculares Nacionais e a relação entre instrução/aprendizagem e desenvolvimento}

Inicialmente, é importante localizar esta discussão no atual cenário educacional e nas políticas que orientam a educação dos alunos com necessidades educacionais especiais. Hoje, no Brasil, a proposta para esse grupo de alunos é regulamentada no Atendimento Educacional Especializado - o AEE. Os alunos arrolados como público-alvo desse atendimento estão em três grupos: alunos com deficiência (auditiva, visual, mental, física, múltipla), alunos com transtornos globais do desenvolvimento (autismo e psicose) e alunos com altas habilidades/superdotação (BRASIL, 2010).

A tarefa de organizar as adaptações curriculares, de acordo com as necessidades do aluno e em consonância com as políticas, cabe tanto ao profissional especializado da sala de recursos, como ao professor da classe regular. Deve, então, ser um trabalho em equipe visando o desenvolvimento das potencialidades do aluno.

Adaptação curricular é uma definição bastante ampla. Nos Parâmetros, são classificados níveis de adaptação curricular: adaptações no nível do projeto pedagógico, adaptações relativas ao currículo da classe, adaptações individualizadas 
do currículo, adaptações de acesso ao currículo e adaptações nos elementos curriculares. O mesmo documento prevê ainda dois tipos de adaptação: adaptações não-significativas do currículo e adaptações curriculares significativas. O primeiro tipo é o predominante e se refere a modificações que o próprio professor pode realizar no planejamento e na execução das atividades; são pequenos ajustes no contexto cotidiano da sala de aula. Já, as adaptações curriculares significativas são estratégias diante de dificuldades mais sérias de aprendizagem; implicam em mudanças de maior porte e que demandam uma avaliação minuciosa e discussão com outros profissionais e familiares. Com elas, buscam-se soluções para o fracasso do processo ensinoaprendizagem que, tradicionalmente, vinham-se pautando nas limitações do sujeito. Tais adaptações têm como pressuposto focar as possibilidades, capacidades, e o potencial do aluno ao invés de demarcar o seu déficit (BRASIL, 1998).

De acordo com os Parâmetros Curriculares Nacionais, qualquer adaptação deve ser construída considerando os seguintes critérios:

- o que o aluno deve aprender;

- como e quando aprender;

- que formas de organização do ensino são mais eficientes para o processo de aprendizagem;

- como e quando avaliar o aluno (BRASIL, 1998, p. 33).

Estes critérios são importantes para determinar quais elementos, processos, objetivos, métodos, apoios, ajustes, etc. necessitam ser implementados para o pleno acesso e aproveitamento do currículo. Eles visam promover "não um novo currículo, mas um currículo dinâmico, alterável, passível de ampliação, para que realmente atenda a todos os alunos" (BRASIL, 1998, p. 33).

Localizada a discussão, parte-se para o fundamento teórico da mesma. Este está na ideia vygotskiana de que aprendizagem promove desenvolvimento: "la instrucción se adelanta en lo fundamental al desarrollo" (VYGOTSKI, 1993, p. 237). Analisando as relações entre o desenvolvimento e a aprendizagem, o teórico concluiu que ambos não são independentes, mas que também não se confundem; havendo complexas relações entre eles: a instrução, o processo de aprendizagem, se adianta ao desenvolvimento, promove desenvolvimento, contudo não se pode estabelecer pré-relações entre os processos, não há uma correspondência contínua entre eles. Vygotski destaca:

Como hemos visto, la instrucción puede proporcionar al desarrollo más de lo que encierran sus resultados directos. Aplicada en un punto de la esfera del pensamiento infantil, modifica y reestructura otros muchos pontos. Puede tener consecuencias en el desarrollo no solo próximas, sino lejanas. La instrucción puede no limitarse a ir tras el desarrollo, a seguir su ritmo, sino que puede adelantarse a él, haciéndolo avanzar y provocando en él nuevas formaciones. (1993, p. 223, grifos no original) 
A instrução traz à tona novas formações, alavanca o desenvolvimento. Daí a importância que Vygotski atribuía à escolarização. A aprendizagem dos conceitos científicos ampliaria o desenvolvimento infantil, criando condições para os sujeitos se apropriarem do conhecimento construído na sociedade, tornando-o seu. No entanto, não se pode entender a internalização desse conhecimento como processo simples, automático. Há uma série de pré-requisitos para que a instrução, de fato, suceda em desenvolvimento; o mais importante é o que considera a zona de desenvolvimento proximal, ou seja, o que demanda que a instrução incida na zona de desenvolvimento proximal do aluno.

O conceito de zona de desenvolvimento proximal aponta para o potencial de desenvolvimento do indivíduo, para suas possibilidades. Em se tratando de pessoas com necessidades educacionais especiais é muito importante, pois auxilia a pensar para além das dificuldades e do déficit, enxergando aspectos latentes no desenvolvimento: funções e conhecimentos que existem em potencial e que precisam de acompanhamento inicial para se efetivar e se transformar em desenvolvimento real. Vygotski ilustra esse conceito:

A zona de desenvolvimento proximal define aquelas funções que ainda não amadureceram, mas que estão em processo de maturação, funções que amadurecerão, mas que estão presentes em estado embrionário. Essas funções poderiam ser chamadas de "brotos" ou "flores" do desenvolvimento, ao invés de "frutos" do desenvolvimento. (VYGOTSKY, 1991, p. 97)

Desse modo, o nível de desenvolvimento de cada aluno deve ser avaliado considerando também o potencial das funções e conhecimentos em amadurecimento, e não apenas os já amadurecidos. Aqui, retorna a ideia de que a aprendizagem desperta o processo de desenvolvimento. Então, para que os "brotos" e "flores" amadureçam e se tornem "frutos", é essencial o sujeito defrontar-se com processos de instrução/ aprendizagem.

A partir dessa ideia, entende-se que a instrução deve se orientar pela zona de desenvolvimento proximal, pelos processos não consolidados, mas em fase de maturação. Desse modo, pensa-se que a definição do quê, como e quando ensinar, bem como das formas de organização do ensino e da avaliação - aspectos levados em conta para a elaboração das adaptações curriculares - deverão estar atreladas à concepção de zona de desenvolvimento proximal.

Retomando o que Vygotski (1991, 1993) propunha, vê-se que o bom ensino é aquele que se adianta ao desenvolvimento, contudo, esse ensino não pode ir muito além das possibilidades do sujeito. Vygotski acreditava que as tarefas que o sujeito consegue fazer com auxílio, aquelas que consegue fazer por imitação, são bons índices do que está em potencial na zona de desenvolvimento proximal. Ele também dizia que não adianta ensinar ao sujeito o que ele já sabe, mas, se deve sempre colocá-lo em situações nas quais possa avançar. Sendo assim, podemos imaginar as adaptações curriculares também como um modo de colocar o conceito de zona de desenvolvimento proximal em funcionamento, ao buscar definir os procedimentos 
didáticos necessários, direcionando a instrução àqueles processos latentes que, a partir da colaboração, transformar-se-ão em desenvolvimento real.

\section{Os conceitos científicos como promotores do desenvolvimento}

Vygotski (1993), ao falar em conceitos científicos, refere-se àqueles conceitos que são aprendidos mediante instrução, prioritariamente em ambientes formais de ensino.

El desarrollo del concepto científico de carácter social se produce en las condiciones de proceso de instrucción, que constituye una forma de cooperación sistemática del pedagogo con el niño. Durante el desarrollo de esta cooperación maduran las funciones superiores del niño con la ayuda y la participación del adulto. (VYGOTSKI, 1993, p. 183)

Os conceitos científicos seriam imprescindíveis para o desenvolvimento do sujeito, para o desenvolvimento das funções psicológicas superiores, ainda na esteira da tese de que a aprendizagem promove desenvolvimento. Ao explicar o processo de formação de conceitos científicos, Vygotski exemplifica essa tese:

[...] los conceptos científicos establecen una parcela de desarrollo que el niño no ha recorrido aún, si la asimilación del concepto científico se anticipa, es decir, se produce en una zona en que aún no han madurado las posibilidades correspondientes, comenzaremos a darnos cuenta de que la enseñanza de los conceptos científicos puede desempeñar en realidad un enorme y decisivo papel en el desarrollo mental del niño. (1993, p. 255)

Os conceitos científicos incidem exatamente naquelas funções/ aprendizagens que a criança ainda não desenvolveu por conta própria. Na situação de ensino, o professor (ou outro colega mais adiantado em relação ao entendimento de um determinado conceito) auxilia a criança a se apropriar desse conhecimento e, dessa forma, vai alargando o potencial de aprendizagem da criança e tornando efetivas algumas compreensões. Assim, nesse processo, a criança avança no desenvolvimento devido à mediação do professor ou do colega no movimento de internalização dos conceitos científicos.

Para explicar os conceitos científicos, Vygotski compara-os aos conceitos cotidianos. O autor (VYGOTSKI, 1993) argumentava que a formação dos conceitos cotidianos (ou espontâneos) está relacionada à experiência direta com o meio, enquanto que os conceitos científicos estão ligados às tarefas e motivos que aparecem na escolarização. Dito de outra forma, os conceitos cotidianos surgem na esfera do perceptual, do concreto, são abstrações a partir do objeto; enquanto os conceitos científicos são abstrações de outra ordem, mais elevadas, formadas a partir dos conceitos cotidianos. A origem distinta do conceito cotidiano, ligada ao objeto, e do conceito científico, balizada por outros conceitos, confere-lhes características e caminhos de desenvolvimento opostos. 
Apesar das características opostas das duas formações conceituais, elas não seguem caminhos isolados, mas sim, ao longo de seu desenvolvimento, estabelecem íntimas relações que contribuem para o avanço de ambos os conceitos. Vygotski explicava que:

[...] el desarrollo de los conceptos espontáneos y científicos son procesos que influyen uno en otro continuamente. Por un lado,así debemos desarrollar nuestras hipótesis - el desarrollo de los conceptos científicos habrá de apoyarse de modo indispensable en un determinado nivel de maduración de los conceptos espontáneos, que no pueden ser indiferentes a la formación de los conceptos científicos debido a lo que la experiencia directa nos enseña: el desarrollo de los conceptos científicos resulta posible tan solo cuando los conceptos espontáneos del niño han alcanzado un nivel determinado, propio del comienzo de la edad escolar. Por otro lado, debemos admitir que la aparición de conceptos de tipo más elevado, como son los conceptos científicos, no puede dejar de acusar la influencia de los conceptos espontáneos surgidos con anterioridad, ya que ni unos ni otros están encapsulados en la conciencia del niño, ni están separados por un tabique infranqueable. No fluyen por canales aislados, sino que hallan inmersos en un proceso de continua interacción, que deberá tener el resultado inevitable de que las generalizaciones de estructura superior, propias de los conceptos científicos, produzcan cambios estructurales en los conceptos espontáneos. Al plantear esa hipótesis nos basamos en lo siguiente: cuando hablamos de la evolución de los conceptos espontáneos o científicos, nos referimos al desarrollo de un proceso único de formación de los conceptos, que se realiza en diferentes circunstancias internas y externas, pero singular en cuanto a su naturaleza y no resulta de la lucha, del conflicto entre las formas de pensamiento que se excluyen una a otra desde el mismo comienzo. (1993, p. 194)

A citação é extensa, mas importante para acompanhar o raciocínio pretendido por Vygotski. Não há conflito no desenvolvimento dos conceitos cotidianos e científicos, eles seguem trajetórias que são opostas, mas não se chocam, tampouco transformam-se uns nos outros, mas sim contribuem juntos para o desenvolvimento da criança. Trata-se de um único processo de formação conceitual, uma vez que, apesar das diferentes circunstâncias de formação, conceitos cotidianos e científicos estão em constante interação. Importante pontuar que, na formação de qualquer conceito, o processo não se conclui no momento que o sujeito assimila pela primeira vez o significado do novo termo/conceito; nesse momento, está apenas iniciando seu processo de desenvolvimento - lei que vale tanto para os conceitos cotidianos quanto para os científicos.

Vygotski (1993) vale-se de uma metáfora para explicar o caminho que seguem ambas formações conceituais. Diz que o conceito cotidiano se desenvolve de baixo para cima, ou seja, das propriedades elementares (concretude) às superiores e complexas (abstrações); e o conceito científico de cima para baixo, das propriedades superiores às inferiores. 
Quanto aos pontos débeis e fortes dos dois tipos de conceitos, Vygotski (1993) explica que a força que os conceitos cotidianos têm, em termos de concretude e experienciação, falta-lhes em termos de abstração. Em contrapartida, aos conceitos científicos faltam, muitas vezes, relações com o concreto, características "visualizáveis", pois eles tendem a limitar-se ao simples verbalismo, embora, como ponto forte, apareça sua voluntariedade (ou arbitrariedade) e consciência. Desse modo, a criança, ao utilizar os conceitos cotidianos, não tem consciência deles e lhe é complicado explicá-los; inversamente, ela utiliza voluntariamente o conceito científico e pode conhecer melhor a definição formal deste do que o objeto a que ele se refere.

Ao contrário dos conceitos cotidianos, os conceitos científicos são conscientes desde o princípio. A instrução formal requer que as funções psicológicas do aluno estejam voltadas ao conceito em si; enquanto, nos conceitos cotidianos, a aprendizagem ocorre, como já foi referido, pela vivência, experiência e pela percepção externa, sem a necessária tomada de consciência: "Quando a criança opera com conceitos espontâneos a sua ação mental está voltada para o fenômeno ou objeto e não para o próprio ato de pensamento que o inclui, por isso eles, quase sempre, não são conscientes" (SFORNI, 2004). Assim, nos conceitos cotidianos as relações são empíricas, enquanto que nos conceitos científicos podemos falar em pensamento teórico.

Está aqui o ponto fundamental dos conceitos científicos que proporciona o desenvolvimento cognitivo e reorganização conceitual: eles são conceitos organizados sistematicamente e são aprendidos de forma consciente; "[...] la toma de conciencia viene por la puerta de los conceptos científicos" (VYGOTSKI, 1993, p. 214).

Na escola, os conceitos são aprendidos de maneira sistematizada deixando explícitas as relações de uns conceitos com outros. A tomada de consciência dos conceitos e das formas de organização das redes, das quais os conceitos fazem parte, é fundamental para o desenvolvimento mental.

Nesse sentido, é característica dos conceitos cotidianos a ausência de sistematização, cabendo entre eles apenas relações empíricas. Esses conceitos serão postos num sistema a partir da internalização dos conceitos científicos; os últimos reestruturam o pensamento da criança, elevando-o a um grau superior.

Vygotski (1993) denomina as relações entre os conceitos de relações de comunalidade, ou seja, relações entre o geral e o particular. O autor explica tais relações com um exemplo: a criança que entende e agrupa as palavras cadeira, mesa, armário, divã, estante, mas que ainda não utiliza o conceito de mobília para designar o conceito desses objetos, ainda não estabeleceu relações de comunalidade entre os conceitos que designam tais objetos. Essa criança ainda não consegue

[...] dominar la relación de comunalidad, adquirir el primer concepto superior, que incluye toda la serie de conceptos más 
particulares subordinados a él, dominar una nueva forma de movimiento de los conceptos no sólo en el plano horizontal, sino también en el plano vertical. (VYGOTSKI, 1993, p. 262)

Quando conseguir estabelecer essas relações, estará avançando em seus processos mentais. As relações de comunalidade conferem mobilidade ao pensamento: quanto mais elaboradas mais se consegue ir de uns conceitos a outros por caminhos diversos. Os conceitos científicos são (ou deveriam) apropriados com base na organização de redes de relações que o professor leva o aluno a estabelecer conscientemente ao trabalhar com esses conceitos. No processo de internalização dos conceitos científicos, a criança vai relacionando-os aos conceitos cotidianos já assimilados e organizando-os, na conexão com outros conceitos.

Assim, pode-se dizer que a grande mudança propiciada pela internalização de conceitos científicos não está relacionada à aprendizagem de novos conceitos - crescimento de vocabulário apenas - mas sim, à aprendizagem de conceitos superiores, isto é, de qualidade diferente, envolvendo abstração e consciência de suas relações com outros conceitos. Resumindo, pode-se dizer que o mais importante não é a mudança quantitativa, mas a mudança qualitativa, que essa internalização produz.

A sistematização e conscientização entram na mente da criança através do aprendizado dos conceitos científicos e são posteriormente transferidas para os conceitos cotidianos. "O aprendizado escolar produz algo fundamentalmente novo no desenvolvimento da criança" (VYGOTSKY, 1991, p. 95). Assim, a escola ganha destaque na promoção do desenvolvimento infantil.

Costas (2012) investigando a formação de conceitos científicos em três alunos com necessidades especiais aponta, também, na direção das mudanças que a escolarização traz aos sujeitos:

À medida que esses sujeitos vão imergindo no saber da escola, no entanto, podem-se observar consideráveis mudanças cognitivas, ou seja, eles vão desvencilhando-se cada vez mais da concretude objetal da cotidianidade conceitual, apresentando conceitos cada vez mais próximos do que se entende por científicos. Essas "metamorfoses" não se dão ao acaso, mas são resultado das inúmeras reorganizações internas dessas crianças, que compartilham situações e conhecimentos que são próprios e intrínsecos a processos institucionalizados de ensino. (COSTAS, 2012, p. 129)

Dada a importância dos conceitos científicos, do ensino escolar, para o desenvolvimento do sujeito, retoma-se a reflexão acerca das adaptações curriculares. Sob justificativa de adequar o ensino e o currículo às especificidades dos alunos com necessidades especiais acentuadas, muitas vezes, abre-se mão dos conteúdos escolares formais, pressupondo que não estariam ao alcance deles. Michels (2006) expõe tal preocupação: "Podemos, nessa lógica, cair na armadilha segundo a qual, em nome do respeito à diferença, os alunos sejam excluídos de seu direito ao conhecimento" (p. 409). 
Ao defender a flexibilização/adaptação curricular, pode-se estar legitimando processos de exclusão no cenário da educação que se queria inclusiva. A escola não conseguindo dar conta da aprendizagem de todos os alunos, não sendo capaz de superar a dificuldade histórica de incluir em seu seio os alunos com necessidades especiais, cria mecanismos para camuflar o problema. É preciso, pois, atenção para que, na defesa das diferenças, não se acabe privando os alunos do domínio de conceitos científicos que se mostram essenciais ao desenvolvimento e compreensão do meio em que estão inseridos.

Meira (2011), a partir dos estudos de Patto sobre fracasso escolar, lembra que, na realidade escolar brasileira já se assistiu a implantação de projetos e reformas que "visam prolongar a ilusão da inclusão, principalmente pela via do afrouxamento dos critérios de avaliação utilizados" (p. 94). Esse afrouxamento seria materializado em estratégias com intenção disfarçada de empurrar qualquer aluno para a conclusão da escolarização obrigatória.

Cabe aqui frisar que a defesa do trabalho com os conceitos científicos não vem demonizar a proposta de adaptação curricular. Pelo contrário, as adaptações são necessárias para tornar os conceitos científicos acessíveis. O que se quer alertar é o perigo de desconsiderar a importância do ensino e da aprendizagem formal de conteúdos específicos, em prol de uma educação esvaziada no slogan "aprender com a diferença". Aprender o quê com a diferença? Os conceitos científicos são imprescindíveis para instrumentalizar os estudantes na compreensão do meio; inclusive para serem mais críticos em relação às práticas e políticas a que estão submetidos.

Saviani (2009), na direção das críticas ao aligeiramento e esvaziamento do ensino destinado às classes populares, defende que seja invertida a lógica que o preside, colocando o trabalho com os conteúdos como prioridade:

[...] os conteúdos são fundamentais e sem conteúdos relevantes, conteúdos significativos, a aprendizagem deixa de existir, ela transforma-se num arremedo, ela transforma-se numa farsa. Parece-me, pois, fundamental que se entenda isso e que, no interior da escola, nós atuemos segundo essa máxima: a prioridade de conteúdos, que é a única forma de lutar contra a farsa do ensino. Por que esses conteúdos são prioritários? Justamente porque o domínio da cultura constitui instrumento indispensável para a participação política das massas. Se os membros das camadas populares não dominam os conteúdos culturais, eles não podem fazer valer seus interesses, porque ficam desarmados contra os dominadores, que se servem exatamente desses conteúdos culturais para legitimar e consolidar a sua dominação. (p. 50-51)

Nesse sentido, também se pode falar de como a prática pedagógica é política e ideológica. A ação do professor, ao priorizar determinados conteúdos ou simplesmente deixá-los de lado, sob a alegação da maior relevância de um ensino 
centrado em valores morais e nos princípios da boa convivência, é carregada de sentidos e intenções - ainda que o professor não esteja plenamente consciente deles. Um bom exemplo é o Relatório para a UNESCO da Comissão Internacional sobre Educação para o Século XXI, coordenada por Jacques Delors; no relatório são estabelecidos os quatro pilares da educação: aprender a conhecer, aprender a fazer, aprender a viver com os outros, aprender a ser (DELORS, 1996).

Devido à importância do documento, as ideias nele proclamadas se espalharam rapidamente. E, muitas vezes, se repete o discurso dos quatro pilares sem a consciência crítica das intenções ocultas ali veiculadas. Duarte (2006) é duro no exame dessas teorias e políticas que dominam de pedagogia do "aprender a aprender" e que estão implícitas nesse documento.

Duarte e Saviani, bem como Vygotski, compartilham a defesa das teses marxistas, alertando acerca dos interesses do capital, implicados nesse tipo de discurso, que circula na escola.

Ora, a escola precisa ir além do cotidiano das pessoas e a forma de ela fazer isso é por meio da transmissão das formas mais desenvolvidas e ricas de conhecimento até aqui produzido pela humanidade. Não interessa, porém, à classe dominante que esse conhecimento seja adquirido pelos filhos da classe trabalhadora. (DUARTE, 2012, p. 155)

O conhecimento cotidiano (os conceitos cotidianos, nos termos de Vygotski) é importante e a escola deve sim valorizá-lo; entretanto, somente a partir do conhecimento científico é que se abrem possibilidades de ampliação do universo de conhecimento dos alunos. Se a tônica do ensino nas escolas de periferia, frequentadas pela classe trabalhadora (lembrando que nelas também estão alunos com necessidades especiais incluídos) for a ênfase nos conceitos cotidianos, nas experiências cotidianas, nas vivências locais, que oportunidades de levar os alunos a pensar para além desse espaço se estará possibilitando?

Os conceitos cotidianos são fundamentais, sem eles nem os conceitos científicos têm condições de ser internalizados. "El desarrollo del concepto cotidiano deberá alcanzar un determinado nivel para que el niño pueda asimilar, en general, y tomar conciencia del concepto científico" (VYGOTSKI, 1993, p. 253). Mas é preciso ir além do cotidiano e instrumentalizar os estudantes com os conhecimentos que a humanidade construiu e sistematizou. Assim, terão condições de pensar a própria realidade (o cotidiano) de modo ampliado e mais crítico porque instrumentalizado.

Se os conceitos científicos são fundamentais para o desenvolvimento dos sujeitos, não se justifica balizar o ensino das pessoas com necessidades educacionais especiais em práticas de repetição, sem reflexão, por se acreditar que esses alunos não avançariam até níveis mais altos na aprendizagem. Ora, se é a própria aprendizagem (principalmente dos conceitos científicos) que alavanca o desenvolvimento, é nela que se deve investir os esforços. É imperativo superar a defesa de uma escola inclusiva 
apenas porque nela se aprende a conviver com a diferença; a luta deve ser por uma escola inclusiva onde, de fato, se aprenda - se aprenda conteúdos.

\section{Considerações finais}

Quando se pensa a educação dos alunos com necessidades especiais em escola regular não há como efetivá-la sem considerar a individualização do ensino para atender as especificidades que se apresentarem. As adaptações curriculares aparecem, então, como instrumentos, estratégias para atender as características específicas dos alunos.

O objetivo central das adaptações curriculares é garantir a todos os alunos o acesso e desenvolvimento do currículo, dos conteúdos escolares ou, nos termos de Vygotski, dos conceitos científicos. Parte-se do pressuposto que todos têm potencial para aprender, embora cada um aprenda de forma diferentes.

Todos, sem exceções, podem aprender, mas ninguém aprende exatamente, da mesma forma, no mesmo ritmo e com os mesmos interesses. Flexibilizar ou adaptar o quê (conteúdo), o quando (temporalidade, sequenciação de assuntos), o como (metodologia didática) e os procedimentos adotados na avaliação, é da maior importância para que os aprendizes que apresentam dificuldades desfrutem da igualdade de oportunidades de apropriação do saber, do saber fazer e do saber ser e conviver. Com essas afirmativas estou me referindo à equidade. (EDLER CARVALHO, 2010, p. 110)

Equidade quer dizer tratar todos como iguais considerando as diferenças, significa reivindicar as condições apropriadas a cada sujeito de modo que tenham acesso a uma educação comum e adequada às necessidades específicas. É essa ideia de individualização do comum que perpassa as adaptações curriculares, de modo que todos possam se apropriar dos conceitos científicos, mas cada um a seu modo, a partir de suas possibilidades.

A discussão acerca dos conceitos científicos não deixa dúvidas quanto à importância do ensino escolar para o desenvolvimento dos sujeitos. Embora, diante de alunos com necessidades educacionais especiais que impõe severas dificuldades aos processos de ensinar e de aprender, o professor não pode declinar de sua função de mediar o conhecimento científico.

É no processo de aprendizagem - aqui, especificamente, na aprendizagem de conceitos científicos - que se alargam as possibilidades de desenvolvimento. Falase de mudanças qualitativas de pensamento que vêm à tona a partir da tomada de consciência, pela apropriação dos conceitos científicos mediados, essencialmente na escola. Os conceitos científicos não apenas ampliam o repertório verbal dos sujeitos, mas organizam num sistema esse repertório. Então, a escolarização dos alunos com necessidades especiais deve trazer para primeiro plano a preocupação 
com o ensino-aprendizagem de conceitos científicos. Aí se encontram as alternativas que propiciarão condições de o aluno se apropriar dos conhecimentos e formas de pensamento que lhe conferirão desenvolvimento cognitivo e condições de atuação crítica e ativa na sociedade.

\section{Referências}

BRASIL, Secretaria de Educação Fundamental. Parâmetros curriculares nacionais: Adaptações Curriculares / Secretaria de Educação Fundamental. Secretaria de Educação Especial. - Brasília: MEC / SEF/SEESP, 1998.

BRASIL, Ministério da Educação. Política Nacional de Educação Especial na Perspectiva da Educação Inclusiva. Brasília: Secretaria de Educação Especial - MEC; SEESP, 2008.

BRASIL, Ministério da Educação. Marcos político-legais da educação especial na perspectiva da educação inclusiva. Brasília: Secretaria de Educação Especial, 2010.

COSTAS, F. A. T. Formação de conceitos em crianças com necessidades especiais: contribuições da Teoria histórico-cultural. Santa Maria: Ed da UFSM, 2012.

DELORS, J. (Coord.). Educação: um tesouro a descobrir: relatório para a UNESCO da Comissão Internacional sobre Educação para o século XXI. Paris: UNESCO, 1996. Disponível em: 〈http://unesdoc.unesco.org/images/0010/001095/109590por.pdf`. Acesso em: 30 jul. 2012.

DUARTE, N. Vigotski e o "aprender a aprender": crítica às apropriações neoliberais e pósmodernas da teoria vigotskiana. 4. ed. Campinas: Autores Associados, 2006.

DUARTE, N. Luta de classes, educação e revolução. In: SAVIANI, D.; DUARTE, N. Pedagogia histórico-crítica e luta de classes na educação escolar. Campinas: Autores Associados, 2012.

GIL, A. C. Métodos e técnicas de pesquisa social. 5. ed. São Paulo: Atlas, 1999.

MEIRA, M. E. M. Incluir para continuar excluindo: a produção da exclusão na educação brasileira à luz da psicologia histórico-cultural. In: FACCI, M. G. D.; MEIRA, M. E. M.; TULESKI, S. C. A exclusão dos "incluídos": uma crítica da psicologia da educação à patologização e medicalização dos processos educativos. Maringá: Eduem, 2011.

MICHELS, M. H. Gestão, formação docente e inclusão: eixos da reforma educacional brasileira que atribuem contornos à organização escolar. In: Revista Brasileira de Educação. Rio de Janeiro: ANPEd. v.ll n.33 set./dez.2006.

SAVIANI, D. Escola e democracia: teorias da educação, curvatura da vara, onze teses sobre a educação política. 4l. ed. Campinas: Autores Associados, 2009.

SEVERINO, A. J. Metodologia do trabalho científico. São Paulo: Cortez, 2002.

SFORNI, M. S. de F. Aprendizagem conceitual e organização do ensino: contribuições da teoria da atividade. Araraquara: JM Editora, 2004.

VYGOTSKY, L. S. A formação social da mente: o desenvolvimento dos processos psicológicos superiores. São Paulo: Martins Fontes, 1991. 
VYGOTSKI, L. S. Pensamiento y Lenguaje. Conferencias sobre Psicología. Obras Escogidas II. Madrid: Visor, 1993.

\section{Correspondência}

Adriane Cenci - Universidade Federal de Pelotas, Faculdade de Educação. Alberto Rosa, 154, Centro, CEP: 96010-770 - Pelotas, Rio Grande do Sul, Brasil.

E-mail: adricenci@hotmail.com - flodamiani@gmail.com

Recebido em 04 de fevereiro de 2013

Aprovado em 09 de abril de 2013 